\title{
STRATEGY SELECTION MODEL FOR DEVELOPMENT OF NATURAL GAS DISTRIBUTION SYSTEMS BASED ON AHP/DEA METHODOLOGIES
}

\author{
Branka Tubin-Mitrović, Mirjana Misita, Nikola Vištica
}

Original scientific paper

This paper presents innovative approach in strategy selection for natural gas distribution system development based on model defined. Methodology applied is analytical hierarchy process (AHP) in which one of the criteria is technical efficiency of the system determined by data envelopment analysis (DEA) which is a common tool regulatory authorities use in process of price regulation. Model can also be used for other industry branches aside from energy, and gives ranks that will enable the choice of distribution networks to be further developed. Besides commonly used techno-economic analyses which are used for determination if a certain system should be further developed or not, model presented is based on multi-criteria analysis that includes both technical and economic parameters but also regulatory tools, which is a novel approach in natural gas sector.

Keywords: analytical hierarchy process; DEA; efficiency analysis; linear non-parametric programming; natural gas distribution

Model za izbor strategije razvoja distributivnih sustava za prirodni plin baziran na AHP/DEA metodama

Izvorni znanstveni članak $\mathrm{U}$ radu je prikazan inovativni pristup u odabiru strategije razvoja plinskog distribucijskog sustava na temelju formiranog modela. U radu je primijenjen analitički hijerarhijski proces (AHP) koji kao jedan od kriterija za odabir distribucijskog sustava kojeg će se dalje razvijati, ima tehničku efikasnost sustava ocijenjenu pomoću DEA (data envelopment analysis) metodologije. Ovu metodologiju regulatorna tijela koriste u svojoj praksi u procesu regulacije cijena. Formirani model se može primjenjivati i za druge djelatnosti osim energetskih jer daje listu prioriteta koja omogućava odabir koji distribucijski sustav dalje razvijati. Osim uobičajenih tehno-ekonomskih analiza koje služe za procjenu da li određeni sustav razvijati ili ne, u radu je prikazan model zasnovan na višekriterijskoj analizi koja obuhvaća tehničke i ekonomske parametre, te alate koji se koriste u regulatornoj praksi, što predstavlja novi pristup u odlučivanju u sektoru prirodnog plina.

Ključne riječi: analitički hijerarhijski proces; analiza efikasnosti; DEA; distribucija prirodnog plina; linearno neparametarsko programiranje

\section{Introduction}

When Energy Law in line with EU directives was adopted in Serbia in 2004 [1], the introduction of competition started in the sector of natural gas, in order to improve the efficiency of the sector through the market mechanisms in natural gas supply. Energy Law introduced dual market design in natural gas market, which consists of regulated and non-regulated part. According to Law, distribution system operators (referred to as DSOs) are responsible for safe and reliable delivery of gas, for the functioning, maintenance and development of natural gas systems in a certain geographic area. There are 34 distribution system operators in Serbia with the license for distribution of natural gas. These companies usually deal with the retail of natural gas as well.

Distribution companies are natural monopolies on the territory where they perform their activities. The number of distribution companies differs from country to country, so does their size and the size of market where they distribute gas. Their organization is based on the territory of the municipality to the territory of the region.

According to Eurogas statistical report [2], significant decline in gas consumption that is noted recently, can be explained as a result of mild weather conditions although other factors such as slow economic recovery, the low price of coal coupled with a weak carbon price and growing share of electricity generation from renewable can also play their part. Demand for gas in heating in the commercial and residential sectors has also experienced decrease. However, gas still remains the fuel of choice in the EU for heating and is likely to remain so thanks to the continued investment in highly efficient, modern gas appliances that can deliver significant energy savings and reduce greenhouse gas emissions throughout Europe.

The reasons for this are basically the fact that the markets that use natural gas are already mature. Low levels of population density, characteristics of cities and their topographic properties in some countries constitute very narrow economically viable conditions for higher natural gas usage. Other factors that also limit natural gas demand include increase of energy efficiency in building construction, either by the application of better standards in respect of thermal insulation or by application of heating systems with greater efficiency, or in some countries by increased renewable energy sources application.

The need for this research is in the fact that for the developing gas markets, with recently introduced price regulation, efficiency gains in importance. Especially when according to Eurogas statistical report [2] a decline in gas consumption is noticed, thus inversely affecting the efficiency. Historical development of natural gas systems has led to the situation that today distribution system operation is very fragmented activity thus lacking the economy of scale effect. Introduction of regulation is forcing some distribution companies to face serious problems due to their technical systems inefficiency, sometimes leading to complete abandonment of this energy sector.

The aim of this research was to define a model for strategy selection what distribution system should be further developed, based on real life data, so subjective evaluations can be avoided. When deciding on natural gas distribution network development all aspects should be taken into account, which is highly complicated because conflicting arguments are sometimes in favour of one 
distributor and drawback for the others. In such cases the application of decision making support software i.e. analytical hierarchy process is highly appreciated. Therefore complex problem approach like multi-criteria analysis, and consideration of many conflicting variables like technical, economic and regulatory is important way forward for this industry sector. AHP approach was chosen as a methodological way to come to a solution of what distribution network should be further developed, because there are conflicting interests or criteria. Since there are numerous requests with respect to energy systems to show their efficiency and numerous distribution companies that perform activity of distribution of natural gas in Serbia, AHP was considered to be a justified solution. In order to accurately apply this methodological approach Expert Choice software was applied.

\section{Related work}

Authors like Saaty [3], described analytical hierarchy process (AHP) as a method of measurement that uses ratio scales. In his research he presented whether general optimization problems can be solved using AHP, and how AHP can be applied in resource allocation, predictions or risk analysis.

Others like Vahidnia et al. [4] use AHP in problems with spatial nature or GIS application. Authors propose fuzzy modified AHP for solving uncertainty in decision making. Author say that AHP method is the most applicable tool in spatial problems and GIS application. Fuzzy form of AHP (FAHP) allows treatment of uncertainty in spatial problems.

Analysis of AHP as effective approach in dealing with industrial engineering decision making problems was given by Triantaphyllou and Mann [5]. Authors examined some practical and computation issues involved when AHP method is used in engineering applications. Also, authors note that software package Expert Choice significantly contributed to the wide acceptance of the AHP methodology, but this tool should be used as a decision support tool and not as the means for reaching final decision.

Other authors like Schmoldt, Peterson and Smith [6] noted that managing natural resources is a complex problem because of difficulties in accurately assessing and quantifying changes in social preferences. AHP offers possibility to include social and biophysical criteria for natural resources management. Authors conclude that the AHP flexibility in variety of decision-making scenarios makes it a useful tool for inclusion of different and conflicting participants in objective manner.

Analysis performed by Ishizaka and Labib [7] describes problem modelling, pairwise comparison, judgment scales, synthesis of weights and limitations using software package Expert Choice. Authors noticed that software Expert choice contributes to big success and wide use of the AHP method, but mention that this method still suffers from some theoretical disputes. Main problem in AHP method refers to understanding, explanation and accuracy of results obtained from aggregation of preferences transposed from scales in different units. Also, criteria interdependence is one of AHP limits.

Paper by Satty [8] explains that AHP is theory of measurements through pairwise comparisons and that it relies on experts' judgments to evaluate dominance of one element to another using scale. In this paper, practical example shows calculation of idealized priorities, obtained by normalization of the priorities through dividing it by the largest of the priorities. Author defines results of pairwise comparisons as relative model. Relative model results and ratings model results are two different models, while relative model gives more accurate results. Author emphasized that further development of AHP method should be in developing group decision making, analytic network process, and developing models for predictions and planning.

As Kendrick and Saaty showed [9], AHP is a method that can assist strategy focused organization in managing business processes improvement. Authors indicate that integration of AHP method in Six Sigma is very valuable because business process improvement prioritization decisions involve both tangible and intangible strategic considerations. Authors show linkage between six sigma drivers and evaluation criteria hierarchy, and say that AHP is an adequate tool for investment prioritization because of its availability to involve both tangible and intangible criteria in list of criteria for projects comparisons.

In this research, another methodology was used, data envelopment analysis (DEA) for technical efficiency assessment, as one of the criteria. This is a newly applied criterion that energy regulatory authorities use when deciding on price levels in application of incentive based regulation principles [10]. Gas distribution, transport and public supply are regulated activities in Serbia. Currently the price control regulation "cost plus method" is being applied. Under this method the maximum allowed revenue in the regulatory period is set for each of DSOs i.e. the price of services they provide (distribution charge) which enables a return on justified operating costs as well as a return on assets employed [11]. For example, "incentive based" regulative is implemented in the Czech Republic, France, Germany, the Netherlands and the UK. Italy uses a combination of the two types of regulation. Finally, some countries use a type of regulation "revenue cap" - Finland, Greece, Poland (with cost plus), and Turkey [12]. In order to assess the technical efficiency the methodology applied is non-parametric data envelopment analysis (DEA), in order to avoid the possible mistakes that parametric methods may introduce due to making assumptions regarding technology. The aim that is achieved by application of DEA is definition of an envelope which consists of the characteristics of the most efficient DSO in the sample, and the results are used to calculate the improvements that can be made for DSOs that are not efficient enough. For the definition of the envelope the linear programming is used. According to Farsi et al. [13] the main advantage of parametric methods over nonparametric approaches is the separation of the inefficiency effect from the statistical noise due to data errors and omitted variables. 
Aside from technical system efficiency analysis, some authors propose DEA to be used as a tool in sport like Petrović Đorđević et al. [14].

When the number of alternatives is considered, there are conclusions that multi-criteria ranking method AHP can be applied both on a larger and a smaller number of alternatives. For a larger number of alternatives it is simpler to make assessment for each alternative in regard to each criterion. For smaller sets of alternatives a pairwise comparison of alternatives in regard to each criterion is more appropriate according to Karleuša et al. [15].

Loron et al. [16] proposed fuzzy theory as a flexible tool for handling various types of uncertainty while applying the AHP and DEA methodology. It can handle the epistemic uncertainty that comes from the lack of information about the actual value of evaluation criteria.

DEA application to network efficiency was also observed for purposes other than regulatory assessments in the process of price regulation as shown by Shirdel, and Mortezaee [17].

According to previous research analysis, there can be observed that integration of DEA methodology as one of criteria into AHP modelling was not introduced. Conventional preference grading of alternatives applicable in AHP, was estimated as insufficient for kind of problems related to natural gas distribution. The specificity of this activity- being subject to regulation of national regulatory authorities, justifies this integration, and makes a key difference in previous natural gas industry related research and this research.

\section{AHP and DEA methodologies}

To make a decision in an organized way to generate priorities, decision needs to be decomposed into the following steps:

1) Definition of the problem.

2) Structuring the decision hierarchy from the top with the goal of the decision, to the objectives from a broad perspective, through the intermediate levels (criteria on which subsequent elements depend) to the lowest level (which usually is a set of the alternatives).

3) Construction of pairwise comparison matrices. Each element in an upper level is used to compare the elements in the level immediately below with respect to it.

4) Use of priorities obtained from the comparisons to weigh the priorities in the level immediately below. This is to be performed for every element. Then for each element in the level below its weighed values are added and its overall or global priority is obtained. Graphic interpretation of decision making model is given in Fig. 1.

This process of weighing and adding continues until the final priorities of the alternatives in the bottom most level are obtained. For comparative analysis of distribution system operators there are several criteria relevant for this purpose. One of them is information about the size of the territory which is to be served by a certain distributor, and a number of citizens in that area to be served. According to the number of citizens and the area served the consumption density is calculated which serves as a criterion for gasification. Based on this result, suggestions on a decision of distribution companies' merger can be made in order to improve this parameter. Besides that it is preferred that the area served is as big as possible it is not the necessary precondition. If in the huge area the number of potential consumers is small, that area is not suitable for gasification because the construction costs of distribution network can be significantly higher than the income from the natural gas sold. Aside from determination of consumption density, other important criteria applicable for distribution system operators' comparative analysis are: number of employees in relation to quantities of natural gas delivered, quantities delivered in relation to distribution network length, technical efficiency according to DEA and increase in delivered quantities by network length increase or number of customers increase. These comparative characteristics are further used in definition of decision making model.

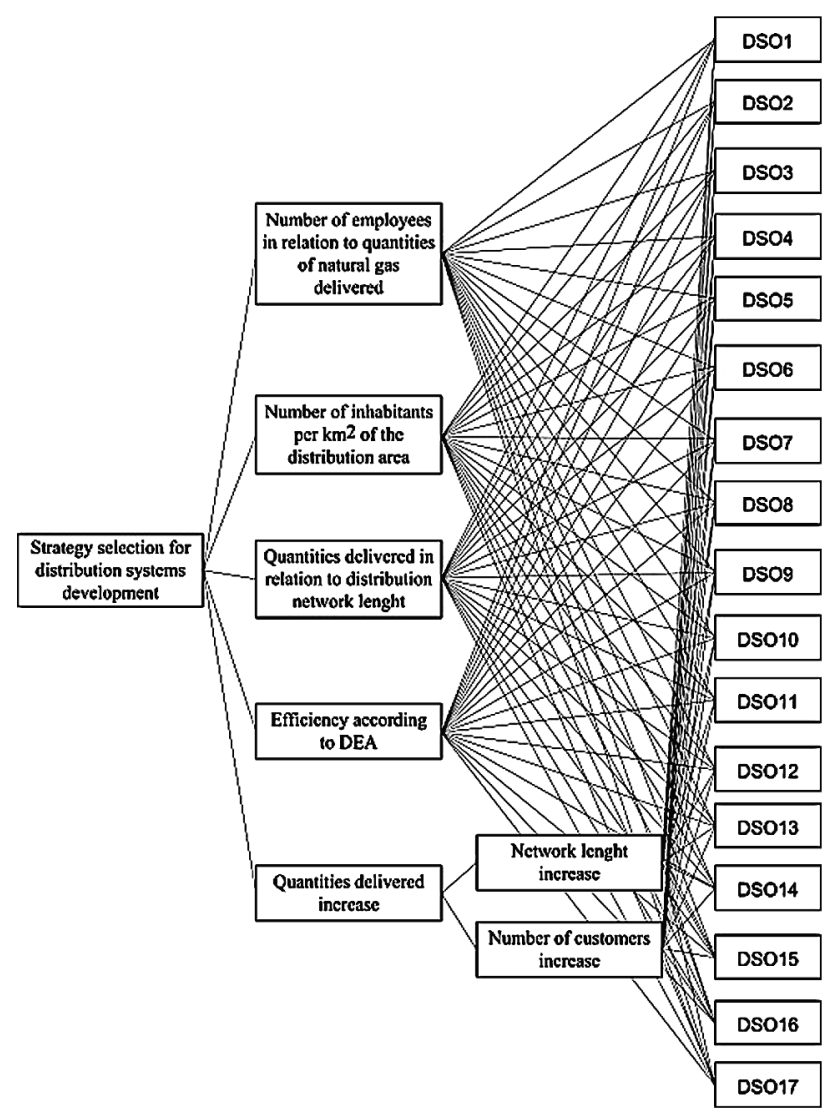

Figure 1 Structure of decision making model

According to Vincova [18], efficiency definition is divided into three aspects of efficiency which are technical, economic and allocative efficiencies. Technical efficiency deals with the relation between inputs and outputs. Economic efficiency deals with the same situation as technical efficiency but in terms of the price. When there are multiple inputs and the reason of the inefficiencies can be related to the mix of inputs used to produce the mix of outputs- it is called allocative efficiency. Non-parametric methods evaluate technical (technological) efficiency focusing on the level of inputs and outputs. Minimizing inputs at a given level of outputs or vice versa leads to being technically efficient. The most commonly used technique in order to measure the 
technical efficiency is DEA. DEA is a non-parametric method that uses linear programming to determine the most efficient company in the sample (frontier).

For each firm, the firm's inputs and outputs are assigned a set of weights to maximize the ratio of weighted outputs to inputs. DEA is a multi-input, multioutput method that focuses on the operational efficiency of the regulated utility. DEA in its simplest form recognizes a firm as being efficient if no other firms are able to produce more output (given its level of input) or to use less of each input (given the level of output).

Fig. 2 illustrates theoretical input-orientated model using two inputs $X_{1}$ and $X_{2}$ (these could be for example capital and labour) to produce a single output $Y$ (delivered energy). The vertical and horizontal axis represents the capital and labour input per unit of output, and the position of a certain company is represented in the picture by real expenses of work and capital per unit of delivered energy $(\mathrm{P})$. The line AA' shows the relative price of the two inputs - it shows all the possible combinations of capital and work engagement, taking into account their relative prices.

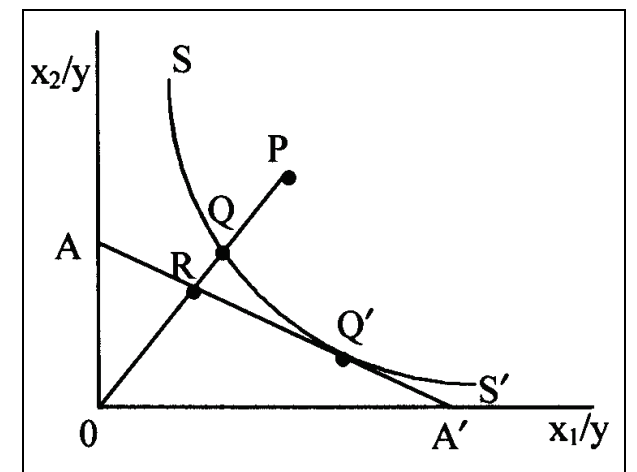

Figure 2 Technical and input-allocative inefficiencies [10]

In Fig. 2 the curve represented by $\mathrm{SS}^{\prime}$ is the measurement of technical efficiency, which represents the possibility of realization of maximum output achievement, for predefined combination of capital and work engagement. If a given firm uses quantities of inputs, defined by point $\mathrm{P}$, to produce a unit of output, technical inefficiency for that firm is represented by the distance $Q P$, i.e. the amount by which all inputs could be proportionally reduced without a reduction in output. This is usually expressed by the ratio $Q P / O P$, which represents the percentage by which all inputs could be reduced. The technical efficiency level (TE) of a firm given in Eq. (1) is most commonly measured by the ratio

$T E_{i}=O Q / O P$

which is equal to one minus $Q P / O P$.

The efficiency of each firm versus the frontier is calculated in terms of a score between zero and one, (with the frontier firms receiving a score of 1) and provides an indicator of the degree of technical inefficiency of the firm. The value of one indicates that the firm is fully technically efficient. For example, point Q is technically efficient because it lies on the efficient unit isoquant.

Efficiency scores are calculated for a firm by comparing it to a linear combination of sample firms that produce as much of each output with the minimum combination of inputs.

Calculating efficiency scores using DEA leads to solving a series of linear problems. Consider a sample consisting of $N$ companies, in this case 17 distribution system operators, each of them using $K$ inputs $(K=1$ since input variable in the model was total costs of DSOs, comprised of operational costs enlarged by the costs for gas losses provision), to produce $M$ outputs ( $M=2$ since output variables were chosen to be technical data such as the number of customers and quantities delivered). The vector $\left(\boldsymbol{X}_{i}\right)$ represents the inputs used by company $(i)$ to produce a set of outputs $\left(\boldsymbol{Y}_{i}\right)$. Suppose now that $(\boldsymbol{U})$ is an $\mathrm{Mx} 1$ vector of output weights and $(\boldsymbol{V})$ a $\mathrm{Kx} 1$ vector of input weights. In that case, the measure of efficiency is given by (Eq. (2)):

$\frac{\boldsymbol{U}^{\mathrm{T}} \boldsymbol{Y}_{i}}{\boldsymbol{V}^{\mathrm{T}} \boldsymbol{X}_{i}}$

That is, efficiency is defined as the weighted ratio of outputs to inputs. By definition, efficiency is a scalar ranging between zero and one, which respectively denote no (0) and full (1) efficiency. Efficiency for company $(i=$ $1, \ldots, 17)$ can now be calculated by finding appropriate values for $(\boldsymbol{U})$ and $(\boldsymbol{V})$. This requires the maximization (Eq. 3) of all efficiency ratios under the constraint that these are equal to, or less than, one (Eq. (4), Eq. (5)). This can be written down as the following optimization problem:

$\max _{\boldsymbol{U}, \boldsymbol{V}} \frac{\boldsymbol{U}^{\mathrm{T}} \boldsymbol{Y}_{i}}{\boldsymbol{V}^{\mathrm{T}} \boldsymbol{X}_{i}}$.

$\frac{\boldsymbol{U}^{\mathrm{T}} \boldsymbol{Y}_{i}}{\boldsymbol{V}^{\mathrm{T}} \boldsymbol{X}_{i}} \leq 1, i=1, \ldots, N$.

$\boldsymbol{U}, \boldsymbol{V} \geq 0$.

Solving this problem, however, leads to an infinite number of solutions. This can be overcome by adding additional constraints (Eq. $(6) \div(9)$ ).

$\max _{\boldsymbol{U}, \boldsymbol{V}} \boldsymbol{U}^{\mathrm{T}} \boldsymbol{Y}_{i}$

This expression maximizes the numerator for the unit being evaluated, trying to assign it the highest possible productivity rating.

$\boldsymbol{V}^{\mathrm{T}} \boldsymbol{X}_{i}=1$.

This expression sets the denominator for the unit being evaluated equal to 1 .

$$
\begin{aligned}
& \boldsymbol{U}^{\mathrm{T}} \boldsymbol{Y}_{j}-\boldsymbol{V}^{\mathrm{T}} \boldsymbol{X}_{j} \leq 0, j=1, \ldots, N . \\
& \boldsymbol{U}, \boldsymbol{V} \geq 0 .
\end{aligned}
$$

Using duality theory, this can then be written down in the most "popular" form for the DEA problem, which is (Eq. $(10) \div(13))$ : 
$\min _{\theta, l} \theta$,

$-\boldsymbol{Y}_{i}+\boldsymbol{Y}_{l} \geq 0$

$\theta_{\boldsymbol{X}_{i}}-\boldsymbol{X}_{l} \geq 0$

$l \geq 0$.

The dual efficiency rating, minimizing $\theta$, requires that the weighted inputs of the other DSOs is less than or equal to the inputs of the DSO being evaluated and that the weighted outputs of the other DSOs is greater than or equal to the DSO evaluated.

In this linear problem format, matrices $\boldsymbol{X}$ and $\boldsymbol{Y}$ represent, respectively, the input and output data space which consists of the individual $\boldsymbol{X}_{i}$ input vector, and $\boldsymbol{Y}_{i}$ output vectors for all $N$ companies. The optimisation problem needs to be run for each company and results in the efficiency score $\theta$ (which is a scalar).

\section{Experimental}

In application of software expert choice and AHP methodology, the first step was to define a problem and structuring decision making problem top down, to define a model. The situation in Serbia is analysed just for the distribution system operators with the license for this activity, this means that all the distribution companies had to have at least seven employees in order to satisfy the conditions prescribed in the Rulebook on licensing [19].

The names of distribution system operators are in the form of distribution system operator "DSO 1", "DSO 2" etc., because of the confidentiality of the information and because for this analysis and the application of the methodology proposed it is irrelevant what distribution companies the data are from. Data were gathered by the information code rules according to which the energy entities regularly report to Energy Agency of the Republic of Serbia (AERS) [20]. The financial and technical data available for this analysis were taken from AERS database and are referring to the year 2012 and were available for 17 out of 34 DSOs. The availability of the accurate data limited the sample size.

First step applied in this research was to decide about problem to be solved-to select a strategy what distribution system should be further developed.

Second step was structuring the decision hierarchy i.e. criteria on which subsequent elements depend. This way, elements for comparisons were chosen:

- number of employees in relation to quantities of natural gas delivered,

- number of inhabitants per $\mathrm{km}^{2}$ of the distribution area (consumption density),

- $\quad$ quantities delivered in relation to distribution network length,

- technical efficiency according to DEA

- quantities delivered increase by,

- network length increase,

- number of customers increase.

In order to satisfy the recommendations related to definition of model with respect to cluster defining, elements that are comparable between the distributors were chosen, and recommendation about their number was taken into account. As one of the aims of hierarchy structure is to diversify between more and less important elements, 5 elements (criteria) were chosen as elements of the same priority, and within the element (criterion) increase of quantities of gas delivered, as lower level elements were network length increase and number of customers increase.

Third step was to define pairwise comparison matrices, for each of the criteria.

Pairwise comparisons were made for distribution companies with respect to their importance, i.e. real life values of certain characteristics were used or the derivatives from the calculations based on real life data. Numerical values of these physical characteristics were entered in the model for pairwise comparisons. At each node of the hierarchy, a matrix collects the pairwise. The judgments are made for a relative value or a quotient $a / b$ of two quantities $a$ and $b$ having the same units $\left(\mathrm{m}^{3}\right.$, meters, $\mathrm{km}^{2}$ and so on).

If the matrix is perfectly consistent, then the transitivity rule (14) holds for all comparisons $a_{i j}$ :

$a_{i j}=a_{i k} \times a_{k j}$

Once the comparisons matrices are filled, priorities can be calculated. The traditional AHP uses the eigenvalue method, based on a consistent matrix with known priorities pi. In this case, the comparison of the alternatives $\mathrm{i}$ and $\mathrm{j}$ is given by $p_{i} / p_{j}$, which multiplied by the priority vector $p$ results in matrix shown in Tab. 1 .

Table 1 Comparison of the alternatives
\begin{tabular}{|c|c|c|c|}
\hline$p_{1} / p_{1}$ & $p_{1} / p_{2}$ & $\ldots$ & $p_{1} / p_{n}$ \\
\hline$p_{2} / p_{1}$ & $p_{2} / p_{2}$ & $\ldots$ & $p_{2} / p_{n}$ \\
\hline$\ldots$ & $\ldots$ & $\ldots$ & $\ldots$ \\
\hline$p_{n} / p_{1}$ & $p_{n} / p_{2}$ & $\ldots$ & $p_{n} / p_{n}$ \\
\hline
\end{tabular}

Comparisons can be grouped as:

$A \vec{p}=n \vec{p}$

where $\vec{p}$ is the priorities vector, $n$ is dimension of the matrix and $\boldsymbol{A}$ is comparison matrix.

Eq. (15) is the formulation of an eigenvector problem. The calculated priorities are exact for a consistent matrix. When slight inconsistencies are introduced, priorities should vary only slightly according to the perturbation theory [9].

For the first criterion (number of employees in relation to quantities of natural gas delivered), there were some recommendations in this respect, according to the analysis held at the Institute Hrvoje Požar. The optimum for natural gas distribution sector is one employee per 1 to 1,5 million $\mathrm{m}^{3}$ of natural gas delivered [21].

The criterion number of employees per delivered quantities, showed that just one DSO (DSO 12) delivered quantities larger than recommended $\left(1 \div 1,5\right.$ million $\mathrm{m}^{3}$ per employee), as shown in Tab. 2.

For this criterion the exact physical values of ratios number of employees and quantities of delivered natural gas were used for pairwise comparisons. 
Table 2 Recommended and realized delivered quantities

\begin{tabular}{|c|c|c|}
\hline & $\begin{array}{c}\text { Realized quantities } \\
\left(\mathrm{m}^{3}\right)\end{array}$ & $\begin{array}{c}\text { Recommended quantities } \\
\left(\mathrm{m}^{3}\right)\end{array}$ \\
\hline DSO 1 & 2761 & 14700 \\
\hline DSO2 & 2557 & 33300 \\
\hline DSO3 & 1301 & 12000 \\
\hline DSO4 & 2645 & 18000 \\
\hline DSO5 & 28812 & 81450 \\
\hline DSO6 & 3873 & 21900 \\
\hline DSO7 & 8063 & 19050 \\
\hline DSO8 & 7418 & 25200 \\
\hline DSO9 & 16187 & 47250 \\
\hline DSO10 & 9808 & 31500 \\
\hline DSO11 & 2095 & 14250 \\
\hline DSO12 & 1064355 & 718500 \\
\hline DSO13 & 1943 & 21600 \\
\hline DSO14 & 8979 & 14400 \\
\hline DSO15 & 296 & 9600 \\
\hline DSO16 & 11428 & 18375 \\
\hline DSO17 & 3350 & 17550 \\
\hline
\end{tabular}

This way relative preference of alternatives (DSO1 : DSO17) with respect to this criterion was obtained, as shown in Tab. 3.

Table 3 Comparison of alternatives with respect to criterion: number of employees/delivered quantities

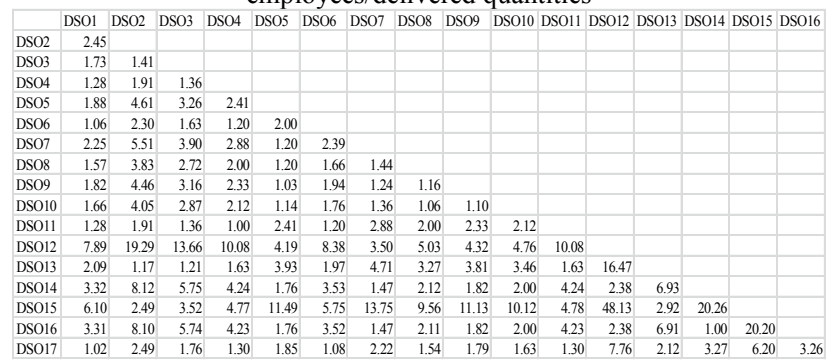

Table 4 Consumption density

\begin{tabular}{|c|c|c|c|}
\hline & $\begin{array}{c}\text { Number of } \\
\text { inhabitants }\end{array}$ & $\begin{array}{c}\text { Distribution } \\
\text { area in } \mathrm{km}^{2}\end{array}$ & $\begin{array}{c}\text { Consumption } \\
\text { density }\end{array}$ \\
\hline DSO1 & 40987 & 487 & 84 \\
\hline DSO2 & 27332 & 239 & 114 \\
\hline DSO3 & 11269 & 305 & 37 \\
\hline DSO4 & 16317 & 284 & 57 \\
\hline DSO5 & 139739 & 1847 & 76 \\
\hline DSO6 & 122320 & 795 & 154 \\
\hline DSO7 & 42092 & 376 & 112 \\
\hline DSO8 & 28227 & 170 & 166 \\
\hline DSO9 & 58754 & 646 & 91 \\
\hline DSO10 & 33722 & 730 & 46 \\
\hline DSO11 & 23925 & 609 & 39 \\
\hline DSO12 & 7498001 & 77474 & 97 \\
\hline DSO13 & 33136 & 362 & 92 \\
\hline DSO14 & 14573 & 596 & 24 \\
\hline DSO15 & 29638 & 427 & 69 \\
\hline DSO16 & 85569 & 1178 & 73 \\
\hline DSO17 & 83022 & 667 & 124 \\
\hline
\end{tabular}

Second criterion-consumption density, was analysed and it can be noted that for five DSOs it is above 100 and for three more between 90 and 100 as can be seen in Tab. 4. So it can be recommended for the possible merger analysis that the limit of 100 should be taken into account.

For this criterion the exact physical values of consumption density (number of inhabitants per $\mathrm{km}^{2}$ of the distribution area) were used, as shown in Tab. 5.

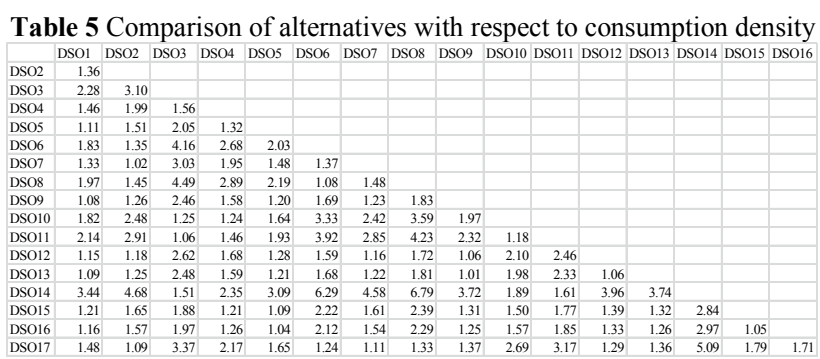

Third criterion, consumption per meter of network, according to the analysis concluded at the Institute Hrvoje Požar, should not be less than $60 \mathrm{~m}^{3} / \mathrm{m}^{\prime}$. This criterion is determined according to techno-economic analysis [21]. When quantities delivered in relation to network length were considered, it was observed that just 2 DSOs satisfy the recommended criterion of $60 \mathrm{~m}^{3} / \mathrm{m}^{\prime}$ of network. For this criterion also the physical values of quantities delivered in relation to network length were used, as shown in Tab. 6.

Table 6 Comparison of alternatives with respect to quantities delivered in relation to network length

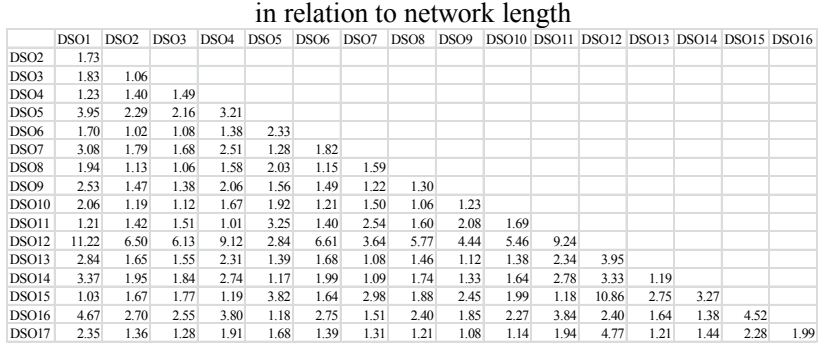

Fourth criterion was technical efficiency according to DEA. The input variable in DEA model was total costs of DSOs, comprised of operational costs enlarged by the costs for gas losses provision, while the output variables were chosen to be technical data such as the number of customers and quantities delivered.

When technical efficiency according to DEA was analysed the results showed significant dispersion i.e. from 0,1 for distributors with very low efficiency to 1 for efficient companies, i.e. technical efficiency revealed very low efficiency for some companies and maximum efficiency rating for others. These results go hand in hand with the view on very heterogeneous structure of natural gas distribution sector in Serbia. Descriptive statistics for the results of technical efficiency given in Tab. 7 support this conclusion.

Table 7 Descriptive statistics

\begin{tabular}{|c|c|c|c|}
\hline & St dev & Average & Coeff varia. \\
\hline $\begin{array}{c}\text { Technical efficiency } \\
\text { scores according to DEA }\end{array}$ & 0,31 & 0,58 & 0,53 \\
\hline
\end{tabular}

Fifth criterion, increase in delivered quantities should lead to greater DSO efficiency, and was graded according to the two criteria of lower hierarchy level - network length increase and number of customers' increase which should both lead to the same result - increase in delivered quantities. For that reason these two sub-criteria were given the same priority in the model and both were graded as "strong" on verbal scale.

When number of employees in relation to network length, quantities delivered in relation to network length, 
consumption density and technical efficiency according to DEA were pairwise compared precise physical values were used, and their ratios were directly entered into the software matrices.

But, when increase in network length and increase in number of delivery points were analysed normalization of physical data had to be introduced.

For network length increase four intervals were defined in a way that the largest network increase reported by the DSO was denoted as maximum and values from zero to that maximum value were divided in four equal intervals. For each of the DSOs their network length increase was attributed to one of the intervals and consequently given the corresponding grade from 1 to 4 . Those grades were used for pairwise comparisons (relative preference of alternatives with respect to this criterion), as given in Tab. 8 .

Table 8 Grades for pairwise comparisons of network length increase

\begin{tabular}{|c|c|}
\hline Network length intervals $(\mathrm{m})$ & Grades for comparisons \\
\hline $0 \div 229676$ & 1 \\
\hline $229677 \div 459000$ & 2 \\
\hline $459001 \div 689000$ & 3 \\
\hline $689001 \div 918000$ & 4 \\
\hline
\end{tabular}

When increase in number of delivery points was analysed, for some networks there was no increase in this criterion or even negative values were observed, because natural gas consumers switch to other fuels or in rural zones the number of households is decreasing.

The same approach as with increase in network length was adopted and four intervals were defined according to percentage increase in number of delivery points, as shown in Tab. 9.

Table 9 Grades for pairwise comparisons of number of delivery points increase

\begin{tabular}{|c|c|}
\hline $\begin{array}{c}\text { Increase in number of delivery } \\
\text { points in } \%\end{array}$ & Grades for comparisons \\
\hline $0 \div 2,5$ & 1 \\
\hline $2,5 \div 5$ & 2 \\
\hline $5 \div 7,5$ & 3 \\
\hline $7,5 \div 10$ and more & 4 \\
\hline
\end{tabular}

Finally, the overall grade was obtained, when comparing the criteria with respect to highest hierarchy level-goal (strategy selection). Criteria technical efficiency according to DEA was given the highest priority in comparison to others, i.e. it was graded as "very strong" on verbal scale. Verbal scale for criterion comparisons can be seen in Fig. 3. This criterion was given the utmost importance because it includes the costs of distribution service and because it serves in a process of price determination in models with incentive based regulation approach. The criterion number of employees in relation to network length was graded as "moderate" on verbal scale because there are certain restrictions, i.e. minimum requirements when number and structure of employees is concerned as a request of a licensing procedure [19]. Therefore there are limitations in this respect, about the possible activities DSOs can take in order to reduce the number of employees and improve this criterion.

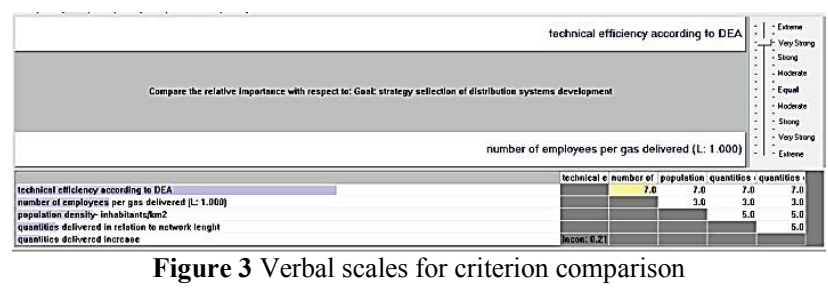

AHP decision making model can be seen in the window of Expert choice software in model view, as shown in Fig. 4.

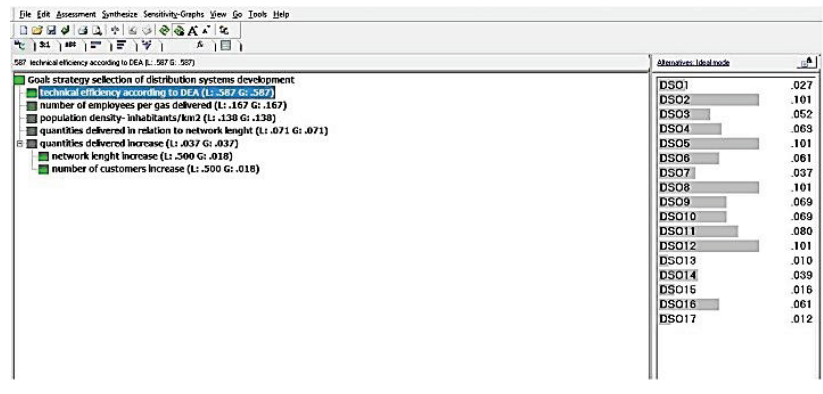

Figure 4 Model view in expert choice software, showing the hierarchy of criteria

The results of the AHP process and the rank of DSOs are determined as shown in Fig. 5. Information was obtained on what distribution system is most favourable to be further developed.

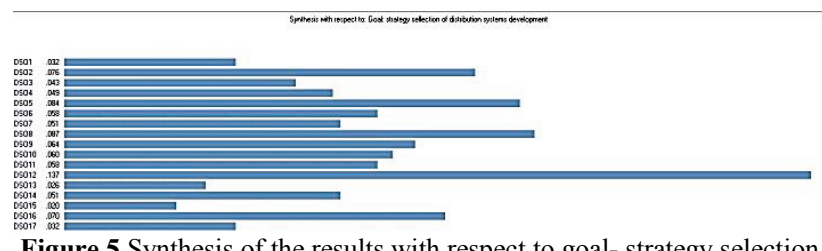

Figure 5 Synthesis of the results with respect to goal- strategy selection of distribution systems development

The results obtained by AHP ranking keep the same ranks as does DEA technical efficiency estimation. This conclusion can be applied for the four best DSOs (DSO12, DSO8, DSO5, DSO2). The difference becomes evident for DSO which gets higher rank according to AHP than according to DEA (DSO16). DSO 16 is one of only two distribution companies that satisfied criterion ratio of quantities delivered and distribution length, and at the same time satisfies criterion ratio of number of employees and delivered quantities. DSO 9 and DSO 10 keep the same rank for both methodologies.

The problem faced during the application of AHP in this research was to define the model and the scale for pairwise comparisons sensitive enough to be applicable to all the dataset, because the sample was constituted of the physical parameters of the distribution companies. The problem was the fact that there are too many distribution companies with very different characteristics. For instance when network length increase was the criterion for pairwise judgments it was noted that there were networks that were not further developed at all for the period in question (year 2012) while some were developed in the amount of hundreds of thousands of meters. Because the sample is so heterogeneous the same problem occurred when number of delivery points was 
concerned because some small and old distribution networks with very low capacity for further number of customers increase were to be compared to new networks that double or triple its number of delivery points within a year.

\section{Conclusions}

Consumption of natural gas has its importance because of its environmental impact (reduction in environmental pollution), because of its reserves and the efficiency of the appliances that use natural gas as source of energy. The need to make optimization with regard to energy efficiency and environmental protection improvements makes an argument in favour of investments for the conversion of other fuels like coal or liquid fuels to natural gas. This process requests distribution networks to be developed in order to make connection of consumers possible. Therefore it is very important to make a model for deciding whether to further develop a certain distribution network or not. Until now, distribution systems in Serbia were developing completely irrespective from one another, and the investments in distribution networks were not controlled in terms of unique criteria or independent justification.

One of the observed characteristics - delivered quantities of gas is shown to significantly influence the overall results and the influence is stronger when relation of employees and quantities is concerned giving the idea of way forward for the improvements.

Since the influence on number of employees is limited because of legal requests, the remaining possibility is to try to improve delivered quantities. This conclusion is also important for the reason of severe decline in consumption on certain networks thus making them inefficient in terms of quantities. When deciding on estimation of preferences for pairwise comparisons within each criterion, the problem faced was extreme dispersion of physical values for all of the criteria chosen, so decision on preferences' values that would be applicable in pairwise comparisons was very difficult. The reason for this is extremely different structure of DSOs in Serbia. They differ in terms of number of customers, quantities delivered, consumers' categories, network length, consumption density. Namely, all of the parameters that are usually used as remarkable for a company which performs distribution of natural gas can be described as highly dispersive. Therefore, comparison of companies within the natural gas distribution sector is highly difficult.

The contribution of this research is integration of DEA methodology into AHP model, because it is a regulatory tool used for determination of technical efficiency and takes into account very important influencing factors both economic and technical such as operational costs as well as distribution network losses. This improves the overall complexity of AHP decision making model.

Another contribution is that alternatives preferences in the model were based on real life physical data, while for the criterion of technical efficiency they were determined by DEA methodology, but also based on the data provided by the industry.
The results imply the characteristic to be improved if a distribution system is to enhance its assessment for further development. They can be further analysed in expert choice software by application of different dynamic graphs, i.e. sensitivity analysis, which enables to change input values and obtain the effect on the final rank or can be used to check whether and how changing in priorities influences alternatives.

In previous experience this kind of approach was not applied when decisions were to be made with regard to investments in energy infrastructure. Common approach in this kind of problems is mainly focused on technoeconomic viability while this model introduces other influencing aspects. Considering the energy market development processes led by the EU authorities, and significance of the energy sector for each country`s development strategy, taking into account the regulatory tools sometimes can be crucial for a company`s viability and a certain industry sector as a whole.

It would be useful for future analysis to take into account effects of distribution system operators' mergers, environmental impact and the influence of introduction of gas distribution price regulation on final results. When considering possible distributors' mergers analysis, the results of this research could be used in respect to relation of number of employees and delivered quantities, delivered quantities and network length, and consumption density. This analysis could show if distributors ' mergers on the level of region would lead to better ratios or increased area for which they are titled to perform the distribution of natural gas, which would seem as a logical activity for companies whose distribution areas are next to each other.

Since investments in gas sector are by its nature financially intensive, time consuming, the influencing factors are often conflicting, so up-to-date approaches in decision making processes are not only appropriate but obligatory.

\section{References}

[1] Energy Law, Official Gazette of the Republic of Serbia, $84 / 2004$.

[2] Eurogas statistical report (2014), Brussels, from http://eurogas.org, (2015-07-07).

[3] Saaty, R. W. The Analytic Hierarchy process - what it is and how it used. // Mathematical Modelling. 9, 3-5(1987), pp. 161-176. DOI: 10.1016/0270-0255(87)90473-8

[4] Vahidnia, M. H.; Alesheikh, A.; Alimohammadi, A.; Bassiri, A. Fuzzy analytical hierarchy process in GIS application. // The International Archives of the Photogrammetry: Remote Sensing and Spatial Information Sciences. 37(B2), (2008), pp. 593-596.

[5] Triantaphyllou, E.; Mann, S. H. Using the Analytic Hierarchy Process for Decision Making in Engineering Applications: Some Challenges. // Journal of Industrial Engineering: Applications and Practice. 2, 1(1995), pp. 3544.

[6] Schmoldt, D. L.; Peterson, D. L.; Smith, R. L. The analytic hierarchy process and participatory decision making. // In Power, J. M.; Strome, M.; Daniel, T. C. (eds.), Proceedings of the $4^{\text {th }}$ International Symposium on Advanced Technology in Natural Resources Management. American Society of Photogrammetry and Remote Sensing, Bethesda, MD. (1995), pp. 129-143. 
[7] Ishizaka, A.; Labib, A. Analytic Hierarchy Process and Expert Choice: Benefits and limitations. // OR Insight. 22, 4(2009), pp. 201-220. DOI: 10.1057/ori.2009.10

[8] Satty, T. Decision making with the analytic hierarchy process. // Int. J. Services Science. 1, 1(2008), pp. 83-99. DOI: $10.1504 /$ IJSSCI.2008.017590

[9] Kendrick, J. D.; Saaty, D. Use Analytic Hierarchy Process for Project Selection. // Six Sigma Forum Magazine. 6, 4(2007), pp. 22-29.

[10] KEMA. Distribution Benchmarking - Activities for Electricity and Gas, Report, Project - Technical Assistance to the Energy Agency of the Republic of Serbia, Belgrade, 2008.

[11] Official Gazette of the Republic of Serbia, Access to and Use of Natural Gas Distribution System Charging Methodology, No. 68/06, 1/07, 100/08, 116/08 and 64/10, Energy Agency of the Republic of Serbia, from http://www.aers.rs, (2015-2-14).

[12] Mapping power and utilities regulation in Europe (2013). ETGM limited, from http://www.ey.com, (2015-02-01).

[13] Farsi, M. et al. Cost efficiency in the Swiss gas distribution sector. // Energy Economics. 29, (2007), pp. 64-78. DOI: 10.1016/j.eneco.2006.04.006

[14] Petrović Đorđević, D. et al. Measuring efficiency of football teams by multi-stage DEA model. // Tehnički Vjesnik. 22, 3(2015), pp. 763-770. DOI: 10.17559/TV20140306134047

[15] Karleuša, B. et al. Improving decision making in defining priorities for implementation of irrigation plans using AHP methodology. // Tehnički Vjesnik. 21, 3(2014), pp. 673680.

[16] Loron, A. S. et al. An integrated fuzzy analytic hierarchy process-fuzzy data envelopment analysis (FAHP-FDEA) method for intelligent building assessment. // Tehnički Vjesnik. 22, 2(2015), pp. 383-389. DOI: 10.17559/TV20140428223907

[17] Shirdel, G. M.; Mortezaee, A. A DEA-based approach for the multi-criteria assignment problem. // Croatian Operational Research Review. 6, (2015), pp. 145-154. DOI: 10.17535/crorr.2015.0012

[18] Vincova, K. Using DEA models to measure efficiency. // BIATEC, National Bank of Slovakia. 8, (2005).

[19] Rulebook on licensing (2015). Official Gazette of the Republic of Serbia 87/2015, from Energy Agency of the Republic of Serbia, http://www.aers.rs, (2015-5-10).

[20] Information code, Energy Agency of the Republic of Serbia, from http://www.aers.rs, (2015-3-17).

[21] Tubin-Mitrović, B. Model for strategy selection of natural gas distribution. // Conference Gas 2011, Kladovo.

\section{Authors' addresses}

Branka Tubin-Mitrović, PhD candidate Energy Agency of the Republic of Serbia Terazije 5, 11000 Belgrade, Serbia E-mail: branka.tubin@aers.rs

Mirjana Misita, Associate Professor Faculty of Mechanical Engineering Kraljice Marije 16, 11000 Belgrade, Serbia E-mail:mmisita@mas.bg.ac.rs

Nikola Vištica, director Gas and Oil division Croatian Energy Regulatory Agency Ulica grada Vukovara 14, 10000 Zagreb, Croatia E-mail: nvistica@hera.hr 